\title{
Are glomerular volume differences between type 1 and type 2 diabetic patients pathologically significant?
}

\author{
K. E. White • S. M. Marshall • R. W. Bilous
}

Received: 6 September 2006 / Accepted: 1 February 2007 / Published online: 27 February 2007

(C) Springer-Verlag 2007

\begin{abstract}
The observation that patients with type 2 diabetes tend to have larger glomeruli than patients with type 1 diabetes was first made more than 10 years ago. It has also been noted that type 2 diabetic patients with nephropathy often have more heterogeneous renal function and structure than type 1 patients. However, whether these observations are linked or have any bearing on the progression of nephropathy in the two types of diabetes remains uncertain. Here we put forward several hypotheses as to why glomerular volume in type 1 differs from that in type 2 diabetes. We suggest that although type 1 and type 2 diabetic patients appear to progress through similar stages of diabetic nephropathy, the route they take may differ. Differences in the way in which the glomeruli respond to the diabetic milieu may enable some type 2 diabetic patients to preserve their filtration surface in the face of an expanding mesangium.
\end{abstract}

Keywords Diabetic nephropathy · Glomerular filtration rate $\cdot$ Glomerular volume $\cdot$ Proteinuria

\section{Abbreviations \\ MGV mean glomerular volume \\ GBM glomerular basement membrane}

K. E. White $(\square) \cdot$ S. M. Marshall

School of Clinical Medical Sciences, Medical School,

Newcastle University,

Framlington Place,

Newcastle upon Tyne NE2 4HH, UK

e-mail:k.e.white@ncl.ac.uk

R. W. Bilous

James Cook University Hospital,

Middlesbrough, UK

\section{Introduction}

Nephropathy in both type 1 and type 2 diabetes is characterised by proteinuria, declining GFR and increasing blood pressure $[1,2]$. The development of glomerular and interstitial lesions is also common to the two types of diabetes [3-6]. However, the reported rate of progress varies, particularly in type 2 diabetic patients, where the decline in GFR can range from +3.1 to $-22.0 \mathrm{ml} \mathrm{min}^{-1}$ year $^{-1}[2,7-9]$. In type 1 diabetic patients, the average rate of decline is $10 \mathrm{ml} \mathrm{min}{ }^{-1}$ year $^{-1}$ in those with poorly controlled blood pressure and $4.8 \mathrm{ml} \mathrm{min}^{-1}$ year $^{-1}$ in those with good blood pressure control [10].

We and others have shown that structural-functional relationships are similar in type 1 and 2 diabetic patients with clinical proteinuria $[4,11]$. However, there is greater heterogeneity of structural lesions and GFR in both microalbuminuric and proteinuric type 2 diabetic patients $[4,8$, $12,13]$. Some type 2 diabetic patients have a relatively well preserved GFR despite increased proteinuria and blood pressure; this may be related to the more pronounced glomerular enlargement that is seen in these patients [4]. Glomerular enlargement is a well recognised feature of diabetes and has been noted at both early (microalbuminuric) and late (proteinuric) stages of nephropathy [14]. There is some debate as to whether this enlargement is an adaptive response, or whether glomerular enlargement itself accelerates glomerulopathic change [15].

In this paper we bring together data from previous studies examining glomerular structure in type 1 and type 2 diabetic patients with albuminuria. Our aim is to explore whether there were any differences in structure that might be related to the observed functional contrasts and to propose hypotheses for the previously observed differences in glomerular volume in type 1 and type 2 diabetic patients. 


\section{Evidence of differences in glomerular volume in type 1 and type 2 diabetic patients}

Mean glomerular volume (MGV) has been estimated in a number of studies in both type 1 and type 2 diabetic patients. However, there are no studies where a direct comparison between the two groups has been made. Østerby et al. measured glomerular volume in type 2 patients and compared the results with those from previously reported type 1 patients [4]. The MGV values were much higher in the type 2 than type 1 diabetic patients (mean [CV]: $6.2[0.42] \times 10^{6}$ vs $2.4[0.26] \times 10^{6} \mu^{3}$ ). In our own studies we have reported values for MGVs that are significantly higher in type 2 [16] than type 1 [17] (5.5 $[0.22] \times 10^{6}$ vs $\left.4.0[0.30] \times 10^{6} \mu \mathrm{m}^{3}, p<0.001\right)$ diabetic patients. Studies in Pima Indians show that MGV is significantly increased as nephropathy progresses, with values in resin-embedded tissue as high as $8.5 \times 10^{6} \mu \mathrm{m}^{3}$ being reported [18].

Variations in tissue preparation can have a significant effect on glomerular volume and therefore comparisons between groups whose samples were processed at different times must be made with caution. However, although the biopsies from the Østerby study were all treated the same way, they were paraffin embedded, which can cause significant tissue shrinkage. The samples from biopsies from our studies were all embedded in epoxy resin, which limits tissue shrinkage [19], and all glomerular volumes were measured using the Cavalieri method [20] .

\section{Is glomerular enlargement due to mesangial expansion?}

Glomerular enlargement occurs in many disease states, including diabetes, and may be either a compensatory or deleterious response [21-23]. It is equally possible that glomerular enlargement does not have a deleterious effect per se, but is simply a consequence of mesangial matrix accumulation and the result, not the cause, of disease progression.

In order to determine what structural parameters contribute to the increase in glomerular volume, we studied both type $1[17]$ and type $2[6,16]$ diabetic patients. The clinical characteristics of the patients are shown in Table 1 and the structural parameters in Table 2.

The characteristic structural changes seen in diabetic patients with nephropathy, i.e. mesangial expansion, increased mesangial matrix and glomerular basement membrane (GBM) thickening, are present in both groups of patients when compared with non-diabetic subjects. There are no significant differences in these variables between the two types of diabetes, and glomerular enlargement is evident in both. Both show a correlation between mesangial volume fraction and proteinuria (type 1: $r=0.55, p<0.001$;
Table 1 Clinical characteristics of 50 type 1 and 15 type 2 diabetic patients with nephropathy

\begin{tabular}{|c|c|c|c|}
\hline & $\begin{array}{l}\text { Type } 1 \\
\text { diabetes }\end{array}$ & $\begin{array}{l}\text { Type } 2 \\
\text { diabetes }\end{array}$ & $p$ value \\
\hline$n$ (male/female) & $50(32 / 18)$ & $15(13 / 2)$ & \\
\hline Age (years) & $38(20-64)$ & $49(31-64)$ & $<0.001$ \\
\hline \multicolumn{4}{|l|}{ GFR } \\
\hline $\mathrm{ml} \mathrm{min}-1.73 \mathrm{~m}^{-2}$ & $102(62-162)$ & & \\
\hline $\mathrm{ml} \min ^{-1}$ & $105(60-187)$ & $116(62-169)$ & \\
\hline $\operatorname{AER}(\mathrm{mg} / 24 \mathrm{~h})^{\mathrm{a}}$ & $147(37-2302)$ & & \\
\hline Proteinuria $(\mathrm{mg} / 24 \mathrm{~h})^{\mathrm{a}}$ & & $640(73-3877)$ & \\
\hline \multicolumn{4}{|l|}{$\mathrm{BP}(\mathrm{mmHg})$} \\
\hline Systolic & $123(97-147)$ & $147(120-185)$ & $<0.001$ \\
\hline Diastolic & 75 (61-89) & $85(67-100)$ & $<0.001$ \\
\hline
\end{tabular}

Data are expressed as mean (range) or ${ }^{\mathrm{a}}$ median (range).

GFR data in type 1 patients have been corrected for body surface area. However, they have also been presented as uncorrected values, as correcting GFR for the type 2 patients is likely to result in overestimation of GFR due to the high BMI of these patients (mean BMI $\left.31 \pm 3 \mathrm{~kg} / \mathrm{m}^{2}\right)$

GFR was measured by iohexol clearance in the type 1 diabetic patients and creatinine clearance in the type 2 diabetic patients. The correlation between these two methods is good except for very high or very low GFRs [52].

type 2: $r=0.60, p=0.019)$. However, only the type 1 diabetic patients show any correlation between MGV and proteinuria $(r=0.44, p=0.006)$, mesangial volume fraction $(r=0.48, p<0.001)$ or GBM width $(r=0.33, p=0.019)$. In the type 1 patients the increase in MGV appears to be due to an increase in solid components, i.e. cells and matrix, whereas the type 2 diabetic patients also show increases in capillary length. This suggests that glomerular enlargement in the type 1 patients may be a direct result of an expanding mesangium, whereas it may represent different adaptive responses in the type 2 patients.

\section{Is glomerular enlargement a compensatory mechanism?}

In diabetes, glomerular enlargement may ameliorate the progression of nephropathy. The glomerulus may enlarge in order to maintain filtration surface area in the face of an expanding mesangium or as a result of a reduction in glomerular number due to occlusion - the remnant glomeruli compensating for the loss [24]. We found no significant difference in the percentage of occluded glomeruli between the type 1 and type 2 diabetic patients in our series; therefore, glomerular loss due to occlusion seems unlikely to account for the differences in glomerular volume.

However, it is possible that other pathological processes may cause non-functioning glomeruli. There is a high frequency of glomerulotubular abnormalities, including atubular glomeruli, in proteinuric type 1 diabetic patients, which 
Table 2 Characteristic glomerular structural parameters of 50 type 1 and 15 type 2 diabetic patients with nephropathy and 14 non-diabetic subjects

\begin{tabular}{|c|c|c|c|c|c|c|c|c|}
\hline & \multicolumn{3}{|c|}{ Type 1 diabetic subjects } & \multicolumn{3}{|c|}{ Type 2 diabetic subjects } & \multirow{2}{*}{$\begin{array}{l}\text { Non-diabetic } \\
\text { control subjects }\end{array}$} & \multirow[t]{2}{*}{$p$ value } \\
\hline & $\begin{array}{l}\text { All } \\
(n=50)\end{array}$ & $\begin{array}{l}\mathrm{M} \\
(n=32)\end{array}$ & $\begin{array}{l}\mathrm{P} \\
(n=18)\end{array}$ & $\begin{array}{l}\text { All } \\
(n=15)\end{array}$ & $\begin{array}{l}M \\
(n=6)\end{array}$ & $\begin{array}{l}\mathrm{P} \\
(n=9)\end{array}$ & & \\
\hline VvMes/Glom & $0.32 \pm 0.09$ & $0.28 \pm 0.08$ & $0.38 \pm 0.08$ & $0.35 \pm 0.13$ & $0.31 \pm 0.10$ & $0.37 \pm 0.14$ & $0.18 \pm 0.03$ & $<0.001^{\mathrm{a}, \mathrm{b}, \mathrm{d}}$ \\
\hline VvMat/Glom & $0.20 \pm 0.06$ & $0.18 \pm 0.05$ & $0.24 \pm 0.06$ & $0.21 \pm 0.09$ & $0.18 \pm 0.08$ & $0.24 \pm 0.10$ & $0.10 \pm 0.02$ & $<0.001^{\mathrm{a}, \mathrm{b}, \mathrm{d}}$ \\
\hline GBMwidth (nm) & $578 \pm 128$ & $534 \pm 108$ & $655 \pm 127$ & $593 \pm 156$ & $551 \pm 121$ & $621 \pm 176$ & $361 \pm 52$ & $<0.001^{\mathrm{a}, \mathrm{b}, \mathrm{d}}$ \\
\hline Caplength (mm) & $29.5 \pm 8.4$ & $28.3 \pm 8.0$ & $31.7 \pm 8.9$ & $44.4 \pm 11.2$ & $45.5 \pm 9.3$ & $43.7 \pm 12.8$ & $25.6 \pm 5.9$ & $0.001^{\mathrm{b}, \mathrm{c}, \mathrm{e}}, 0.008^{\mathrm{f}}$ \\
\hline $\operatorname{Sgbm}\left(\mathrm{mm}^{2}\right)$ & $0.34 \pm 0.11$ & $0.34 \pm 0.11$ & $0.35 \pm 0.11$ & $0.56 \pm 0.25$ & $0.62 \pm 0.17$ & $0.51 \pm 0.29$ & $0.41 \pm 0.10$ & $0.049^{\mathrm{b}}, 0.001^{\mathrm{c}, \mathrm{e}}$ \\
\hline SMCap $\left(\mathrm{mm}^{2}\right)$ & $0.24 \pm 0.09$ & $0.22 \pm 0.08$ & $0.29 \pm 0.08$ & $0.33 \pm 0.09$ & $0.31 \pm 0.10$ & $0.35 \pm 0.07$ & $0.12 \pm 0.06$ & $<0.001^{\mathrm{a}, \mathrm{b}, \mathrm{c}}, 0.004^{\mathrm{d}}, 0.023^{\mathrm{e}}$ \\
\hline $\operatorname{SMUr}\left(\mathrm{mm}^{2}\right)$ & $0.16 \pm 0.06$ & $0.15 \pm 0.06$ & $0.16 \pm 0.06$ & $0.28 \pm 0.07$ & $0.30 \pm 0.09$ & $0.27 \pm 0.04$ & $0.14 \pm 0.03$ & $<0.001^{\mathrm{b}, \mathrm{c}, \mathrm{e}, \mathrm{f}}$ \\
\hline Occluded $(\%)^{\mathrm{d}}$ & $8.3(0-50)$ & $7.8(0-44)$ & $12.1(0-50)$ & $9.7(0-31)$ & $7.1(6-24)$ & $15.5(0-31)$ & N/A & $\mathrm{NS}$ \\
\hline $\begin{array}{l}\text { MGV } \\
\left.\qquad \times 10^{6} \mu \mathrm{m}^{3}\right)\end{array}$ & $4.0 \pm 1.2$ & $3.6 \pm 1.1$ & $4.6 \pm 1.2$ & $5.5 \pm 1.2$ & $5.6 \pm 1.3$ & $5.5 \pm 1.2$ & $3.2 \pm 1.1$ & $0.05^{\mathrm{a}}, 0.004^{\mathrm{d}},<0.001^{\mathrm{b}, \mathrm{c}, \mathrm{e}}$ \\
\hline
\end{tabular}

The diabetic subjects have been divided into those with microalbuminuria $(\mathrm{M})$ and those with clinical proteinuria $(\mathrm{P})$.

$M$ microalbuminuric: type 1: AER $<200 \mu \mathrm{g} / \mathrm{min}$; type 2 : total protein $<500 \mathrm{mg} / 24 \mathrm{~h}$

$P$ proteinuric: type 1: AER $\geq 200 \mu \mathrm{g} / \mathrm{min}$; type 2 : total protein $\geq 500 \mathrm{mg} / 24 \mathrm{~h}$

${ }^{a}$ Type 1 (All) diabetic patients compared with non-diabetic control subjects.

${ }^{\mathrm{b}}$ Type 2 (All) diabetic patients compared with non-diabetic control subjects.

${ }^{\mathrm{c}}$ Type 1 (All) compared with type 2 (All) diabetic patients.

${ }^{\mathrm{d}}$ Microalbuminuric compared with clinically proteinuric type 1 diabetic patients.

${ }^{\mathrm{e}}$ Microalbuminuric type 1 compared with microalbuminuric type 2 diabetic patients.

${ }^{\mathrm{f}}$ Clinically proteinuric type 1 compared with clinically proteinuric type 2 diabetic patients.

There were no significant differences between microalbuminuric and proteinuric type 2 patients.

Data are expressed as mean $\pm \mathrm{SD}$ in or ${ }^{\mathrm{d}}$ median (range).

$V v M e s / G l o m$ volume fraction of mesangium, VvMat/Glom volume fraction of matrix, GBM glomerular basement membrane, Caplength capillary length, Sgbm filtration surface area, SMCap mesangio-capillary surface, SMUr mesangio-urinary surface

may contribute to the decline in GFR [25]. There are no published data on type 2 diabetes, but it is possible that there are fewer atubular glomeruli resulting in better preservation of GFR; or conversely, that there is a higher frequency of atubular glomeruli resulting in glomerular enlargement of the remaining functional glomeruli and subsequent preservation of GFR. This area warrants further investigation.

Capillary length, and the filtration and mesangio-urinary surface areas are all significantly increased in type 2 compared with type 1 patients and non-diabetic control subjects, implying that in type 2 diabetes, glomerular enlargement is a compensatory mechanism, perhaps to a greater extent than in type 1 diabetes. From our current data we hypothesise that the glomeruli are compensating for a reduction in filtration surface secondary to mesangial expansion.

\section{Is glomerular enlargement different at early and late stages of nephropathy?}

In order to compare glomerular volume changes at early and late stages of diabetic nephropathy, we grouped our patients into those with microalbuminuria (type 1: AER $<200 \mu \mathrm{g} / \mathrm{min}$; type 2 : total protein $<500 \mathrm{mg} / 24 \mathrm{~h}$ ) and those with proteinuria (type $1:$ AER $\geq 200 \mu \mathrm{g} / \mathrm{min}$; type 2 : total protein $\geq 500 \mathrm{mg} / 24 \mathrm{~h}$ ). Grouping the type 2 diabetic patients on the basis of total protein rather than albumin excretion could result in some proteinuric patients being wrongly classified as microalbuminuric. However, the distinction between microalbuminuria and proteinuria at AER levels close to $200 \mu \mathrm{g} / \mathrm{min}$ is somewhat arbitrary and it is not possible to discriminate renal structure in patients at this interface [8].

The difference in MGV between type 1 and type 2 diabetic patients is most prominent in microalbuminuric patients (Table 2). In the type 1 diabetic patients, MGV is higher in the proteinuric subjects, whereas MGV is increased in microalbuminuric type 2 patients and there is no evidence of further increases in those with proteinuria. Similar results were found in a group of type 2 diabetic patients studied by Dalla Vestra et al. [26]. This suggests that glomeruli may have a limited capacity for compensatory enlargement and may reach a stage where they are no longer able to resist mesangial expansion and a corresponding decline in filtration surface. This hypothesis is supported by the observed relationship between mesan- 
gial volume fraction and filtration surface seen in proteinuric, but not microalbuminuric, type 2 diabetic patients.

In contrast, it is the proteinuric type 1 diabetic patients that demonstrate increased MGV with corresponding mesangial expansion and loss of filtration surface. As the microalbuminuric patients did not show any signs of compensatory glomerular enlargement, it is possible that nephropathy in type 1 diabetic patients might progress more quickly than in type 2 diabetic patients. Patients who develop nephropathy after a longer duration of diabetes have larger glomeruli than those who develop it after a relatively short duration, i.e. 'fast-trackers' [27]. Thus, the fast-trackers may have a reduced capability for adaptive glomerular enlargement.

\section{Could glomerular enlargement result in increased protein loss?}

The mesangio-capillary surface area (Fig. 1) is significantly increased in both type 1 and type 2 diabetic patients, with greater increases seen in the type 2 diabetic patients. The mesangio-capillary surface is a loose, leaky structure and the rapid entry of small tracers $(<405 \mathrm{~nm})$ into the mesangium within a few minutes of i.v. injection is indicative of a considerable flow of blood plasma into this region. It is likely that this fluid is then filtered across the mesangio-urinary surface, and contributes to the glomerular filtrate [28]. As both mesangio-capillary and mesangiourinary surface areas are significantly increased in the type 2 patients, increased filtration via this pathway could contribute towards sustaining GFR at the same time as

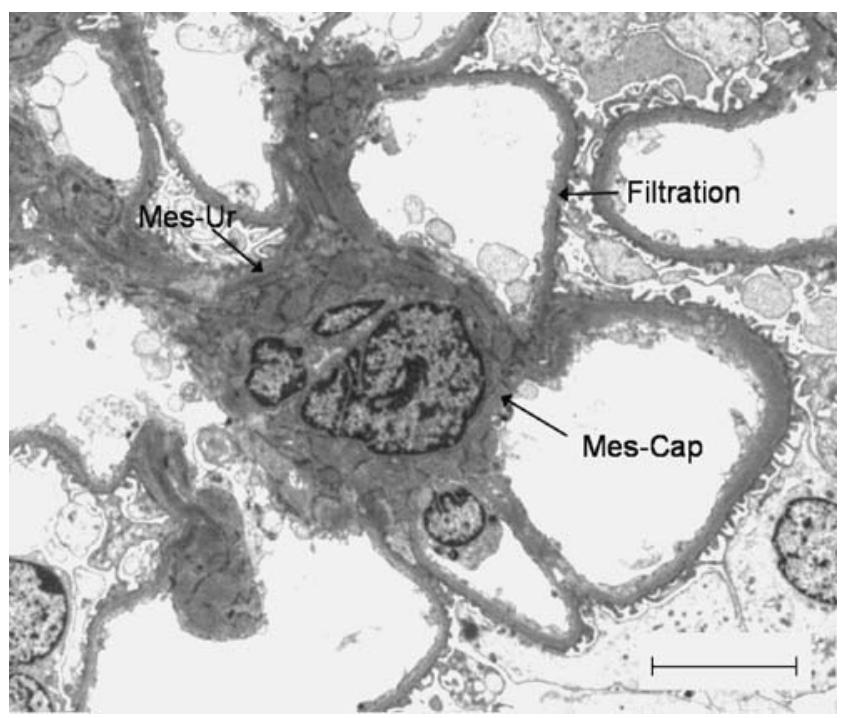

Fig. 1 Electron micrograph showing part of the glomerular tuft. MesCap, mesangio-capillary surface; Mes-Ur, mesangio-urinary surface. Bar, $5 \mu \mathrm{m}$ increasing protein loss, thus explaining in part the paradox of heavy proteinuria with a relatively preserved GFR.

\section{Are the differences due to blood pressure?}

Our type 1 diabetic patients were normotensive as part of the entry criteria for the ESPRIT Study, whereas the type 2 diabetic patients were hypertensive. However, we do not believe this explains the contrasting results. The Minneapolis Group have shown that there is no difference in MGV in normotensive compared with hypertensive type 1 patients [29] and Table 3 (S. M. Mauer, unpublished data). Thus, it is possible that some factor other than blood pressure influences the increase in MGV in the type 2 diabetic patients.

Despite being normotensive, our type 1 diabetic patients demonstrated the characteristic lesions of diabetic glomerulopathy, some to quite an extensive degree; other studies have also reported patients with normotension and classical glomerular lesions [30, 31].Thus we believe that although this group may not be entirely typical, they are representative.

\section{Does age have an influence on glomerular volume?}

Type 2 diabetic patients are significantly older that the type 1 diabetic patients. However, glomerular volume decreases with age in normal man [32]. Therefore, age is unlikely to explain the differences in glomerular volume seen in these patients.

\section{Does duration of diabetes affect glomerular volume?}

In newly diagnosed type 1 diabetes glomerular volume is increased due to an increase in the length and diameter of

Table 3 Data on ten normotensive and ten hypertensive type 1 diabetic patients

\begin{tabular}{llll}
\hline & Normotensive & Hypertensive & $p$ value \\
\hline$n$ (male/female) & $10(5 / 5)$ & $10(6 / 4)$ & \\
Age (years) & $28 \pm 7$ & $38 \pm 8$ & 0.008 \\
Duration of diabetes (years) & $14 \pm 4$ & $21 \pm 7$ & 0.02 \\
GFR $\left(\mathrm{ml} \mathrm{min}{ }^{-1} 1.73 \mathrm{~m}^{-2}\right)$ & $112 \pm 10$ & $70 \pm 30$ & 0.002 \\
AER $\left(\mu \mathrm{g} / \mathrm{min}^{\mathrm{a}}\right.$ & $10(2-117)$ & $443(226-869)$ & $<0.001$ \\
BP $(\mathrm{mmHg})$ & & & \\
Systolic & $134 \pm 12$ & $136 \pm 12$ & $\mathrm{NS}$ \\
Diastolic & $69 \pm 8$ & $79 \pm 8$ & 0.01 \\
MGV $\left(\times 10^{6} \mu \mathrm{m}^{3}\right)$ & $1.9 \pm 0.8$ & $2.2 \pm 0.7$ & $\mathrm{NS}$ \\
\hline
\end{tabular}

Data are expressed as mean $\pm \mathrm{SD}$ in or ${ }^{\mathrm{a}}$ median (range).

Data provided by S. M. Mauer. Biopsies were embedded in paraffin, which results in lower MGV compared with resin-embedded tissue. 
the capillaries, which is only partially normalised after 6 years duration [33]. Our type 1 diabetic patients had a wide range of diabetes duration (2-43 years) and there was no correlation between duration and glomerular volume. However, we have previously shown that type 1 diabetic patients with clinical proteinuria and long duration (2426 years) had larger glomeruli than proteinuric patients of shorter diabetes duration (14-16 years) [27]. In type 2 diabetic patients the time of onset of diabetes is often unknown, but Østerby et al. demonstrated large glomeruli in type 2 diabetic patients with known diabetes duration of only 7 years [4]. The type 2 diabetic patients in our study were re-biopsied after 2 years and there was no significant difference in glomerular volume from baseline to follow-up [34]. Thus the exact influence of duration on glomerular volume is unclear, but there is no evidence to suggest that it is different in type 1 and type 2 diabetes.

\section{Are the differences due to increased BMI in type 2 diabetic patients?}

In normal man there is a positive relationship between body surface area and glomerular volume [32]. The majority of our type 2 diabetic patients are male and have a high BMI, and are therefore likely to have a larger body size than the type 1 diabetic patients. Although within each group there is no difference in glomerular volume between male and female patients, and within the type 2 diabetic patients there is no relationship between BMI and glomerular volume, the high BMI in the type 2 diabetic patients cannot be discounted as a possible contributory cause of increased glomerular volume.

\section{Does ethnicity play a role in glomerular volume?}

Ethnicity does influence glomerular volume. Pima Indians have large glomeruli even in the absence of diabetes [35], with further enlargement once diabetes develops [18]. In addition, a study on renal donors showed that glomeruli are larger in African Americans than Europids [36] and an autopsy study has shown glomeromegaly in non-diabetic Australian Aborigines compared with Australian white subjects [37]. Glomerular enlargement is believed to be related to fewer functioning nephrons in these ethnic groups.

To our knowledge there is no study that has directly compared glomerular volume in diabetic patients from different ethnic backgrounds. Values for glomerular volume in Pima Indians with type 2 diabetes are greater than those measured in our type 2 diabetic patients [18]. However, as the measurements were done by two different laboratories using different methodologies it is difficult to draw firm conclusions. However, as our studies involved mainly Europid patients, differences in ethnic mix cannot explain our observed differences between type 1 and type 2 diabetic patients.

\section{Do haemodynamics play a role in glomerular enlargement?}

Although morphometric analysis can demonstrate structural differences between the type 1 and type 2 diabetic patients, it cannot tell us much about the cause. One possible hypothesis is that there is a variable renal haemodynamic response at the onset of diabetes. Early changes in glomerular haemodynamics have been implicated in the pathogenesis of diabetic glomerulopathy [38]. It has been suggested that the observed loss of autoregulation results in increased glomerular capillary pressure, hyperfiltration and glomerular hypertrophy secondary to increases in capillary length and surface area. These changes take place within 4 days in the diabetic rat [39]. It has been proposed that glomerular hypertrophy secondary to changes in pressure and blood flow results in mechanical stress, mesangial cell stretch, accumulation of matrix and ultimately to the progression of glomerular damage and loss in GFR [40]. This early mechanical stress may damage the compensatory mechanism required to resist mesangial expansion later in the disease.

Loss of autoregulation at onset of diabetes is a feature of both type 1 [41] and type 2 [42] diabetic patients. However, some type 2 diabetic patients are hypertensive at onset and therefore may have a different renal haemodynamic response to patients with type 1 diabetes [43, 44]. In spontaneously hypertensive rats, a model of essential hypertension, glomerular capillary pressure remains normal due to constriction of the afferent arteriole [45]. Although glomerular capillary pressure cannot be measured directly in man, indirect methods have suggested that in patients with essential hypertension the afferent arteriolar resistance is elevated, perhaps secondary to hyalinosis, and glomerular capillary pressure is normal [46]. Patients with essential hypertension have increased glomerular volumes possibly because they also have fewer glomeruli [47]. We hypothesise that those type 2 diabetic patients that have essential hypertension, as opposed to hypertension caused by diabetic kidney damage, may not have experienced any increase in glomerular capillary pressure at onset of diabetes. Consequently, there would be no pressurestretch-induced damage to the compensatory mechanism that permits glomerular enlargement and maintenance of the glomerular filtration surface in the face of mesangial expansion. We would suggest however, that this 'protec- 
tion' is limited and with increasing duration of diabetes, hypertension and nephropathy, patients would follow the route of continuing mesangial expansion with increasing loss of filtration surface. This would explain the different timing and magnitude of glomerular enlargement during the evolution of nephropathy in type 1 and type 2 diabetes.

To test this hypothesis it would be necessary to identify those patients with essential hypertension as opposed to hypertension caused by diabetic renal disease. Arteriolar hyalinosis is a feature of both diabetic and non-diabetic renal disease $[48,49]$, but in diabetes both the afferent and efferent arterioles are affected, whereas in hypertension alone it is restricted to the afferent arteriole [50]. It would be extremely difficult to discern patients using this criterion. Only natural history studies relating changes in blood pressure to arteriolar change can answer this question.

\section{Are differences due to heterogeneity in lesions of type 2 patients?}

It has been suggested that there is more heterogeneity in type 2 glomerulopathy, with up to $63 \%$ of patients demonstrating atypical diabetic lesions [12]. However, in unselected biopsy series this proportion is closer to $10 \%$ [51]. We have shown that type 2 diabetic patients with nephropathy have structural lesions similar to type 1 diabetic patients and the low CVs suggest that there is less heterogeneity than previously thought [11].

\section{Conclusion}

Although type 1 and type 2 diabetic patients with nephropathy have similar clinical and pathological features, there are some subtle differences that may have an important influence on its progression. It is possible that the timing of the development of hypertension may play a role. We would suggest that there are some type 2 diabetic patients who are able to adapt better to developing glomerulopathy and maintain their filtration surface. However, the mechanisms involved in maintaining filtration surface may also be responsible for the increased proteinuria seen in these patients.

It is likely that co-morbid conditions, such as hypertension, seen in type 2 diabetes influence the development of diabetic glomerulopathy and may modify the response of the glomerulus to hyperglycaemia. Natural history studies that relate changes in blood pressure with structural lesions and glomerular volume are required to explore these issues.
Acknowledgements We are grateful to S. M. Mauer for providing biopsy material from non-diabetic control subjects and data from hypertensive type 1 diabetic patients. We also acknowledge members of the ESPRIT and Diabiopsies Study Groups and staff of the Biomedical EM Unit, Newcastle University.

Duality of interest The authors declare that they have no duality of interest in connection with this study.

\section{References}

1. Viberti GC, Bilous RW, Mackintosh D, Keen H (1983) Monitoring glomerular function in diabetic nephropathy. A prospective study. Am J Med 74:256-264

2. Gall MA, Nielsen FS, Smidt UM, Parving HH (1993) The course of kidney function in type 2 (non-insulin-dependent) diabetic patients with diabetic nephropathy. Diabetologia 36:1071-1078

3. Mauer SM, Steffes MW, Ellis EN, Sutherland DE, Brown DM, Goetz FC (1984) Structural-functional relationships in diabetic nephropathy. J Clin Invest 74:1143-1155

4. Østerby R, Gall MA, Schmitz A, Nielsen FS, Nyberg G, Parving $\mathrm{HH}$ (1993) Glomerular structure and function in proteinuric type 2 (non-insulin-dependent) diabetic patients. Diabetologia 36:10641070

5. Lane PH, Steffes MW, Fioretto P, Mauer SM (1993) Renal interstitial expansion in insulin-dependent diabetes mellitus. Kidney Int 43:661-667

6. Cordonnier DJ, Pinel N, Barro C et al (1999) Expansion of cortical interstitium is limited by converting enzyme inhibition in type 2 diabetic patients with glomerulosclerosis. The Diabiopsies Group. J Am Soc Nephrol 10:1253-1263

7. Nelson RG, Bennett PH, Beck GJ et al (1996) Development and progression of renal disease in Pima Indians with non-insulindependent diabetes mellitus. Diabetic Renal Disease Study Group. N Engl J Med 335:1636-1642

8. Nosadini R, Velussi M, Brocco E et al (2000) Course of renal function in type 2 diabetic patients with abnormalities of albumin excretion rate. Diabetes 49:476-484

9. Silveiro SP, Friedman R, de Azevedo MJ, Canani LH, Gross JL (1996) Five-year prospective study of glomerular filtration rate and albumin excretion rate in normofiltering and hyperfiltering normoalbuminuric NIDDM patients. Diabetes Care 19:171-174

10. Rossing P (1998) Promotion, prediction and prevention of progression of nephropathy in type 1 diabetes mellitus. Diabet Med 15:900-919

11. White KE, Bilous RW (2000) Type 2 diabetic patients with nephropathy show structural-functional relationships that are similar to type 1 disease. J Am Soc Nephrol 11:1667-1673

12. Gambara V, Mecca G, Remuzzi G, Bertani T (1993) Heterogeneous nature of renal lesions in type II diabetes. J Am Soc Nephrol 3:1458-1466

13. Parving HH, Gall MA, Skott $P$ et al (1992) Prevalence and causes of albuminuria in non-insulin-dependent diabetic patients. Kidney Int 41:758-762

14. Gundersen HJ, Osterby R (1977) Glomerular size and structure in diabetes mellitus. II. Late abnormalities. Diabetologia 13:43-48

15. Remuzzi G (1994) Glomerular hypertrophy and progression: Summary and concluding remarks. Kidney Int 45(Suppl 45): $\mathrm{S} 30-\mathrm{S} 31$

16. White KE, Bilous RW (2004) Structural alterations to the podocyte are related to proteinuria in type 2 diabetic patients. Nephrol Dial Transplant 19:1437-1440 
17. (2001) Effect of 3 years of antihypertensive therapy on renal structure in type 1 diabetic patients with albuminuria: the European Study for the Prevention of Renal Disease in Type 1 Diabetes (ESPRIT). Diabetes 50:843-850

18. Pagtalunan ME, Miller PL, Jumping-Eagle S et al (1997) Podocyte loss and progressive glomerular injury in type II diabetes. J Clin Invest 99:342-348

19. Miller PL, Meyer TW (1990) Effects of tissue preparation on glomerular volume and capillary structure in the rat. Lab Invest 63:862-866

20. Lane PH, Steffes MW, Mauer SM (1992) Estimation of glomerular volume: a comparison of four methods. Kidney Int 41:1085-1089

21. Yoshida Y, Fogo A, Ichikawa I (1989) Glomerular hemodynamic changes vs hypertrophy in experimental glomerular sclerosis. Kidney Int 35:654-660

22. Zatz R, Fujihara CK (1994) Glomerular hypertrophy and progressive glomerulopathy. Is there a definite pathogenetic correlation? Kidney Int Suppl 45:S27-S29, discussion S30-S21

23. MacKay K, Striker LJ, Stauffer JW, Agodoa LY, Striker GE (1990) Relationship of glomerular hypertrophy and sclerosis: studies in SV40 transgenic mice. Kidney Int 37:741-748

24. Osterby R, Gundersen HJ, Nyberg G, Aurell M (1987) Advanced diabetic glomerulopathy. Quantitative structural characterization of nonoccluded glomeruli. Diabetes 36:612-619

25. Najafian B, Crosson JT, Kim Y, Mauer M (2006) Glomerulotubular junction abnormalities are associated with proteinuria in type 1 diabetes. J Am Soc Nephrol 17(Suppl 2):S53-S60

26. Dalla Vestra M, Masiero A, Roiter AM, Saller A, Crepaldi G, Fioretto P (2003) Is podocyte injury relevant in diabetic nephropathy? Studies in patients with type 2 diabetes. Diabetes 52:1031-1035

27. Bilous RW, Mauer SM, Sutherland DE, Steffes MW (1989) Mean glomerular volume and rate of development of diabetic nephropathy. Diabetes 38:1142-1147

28. Latta $H$ (1992) An approach to the structure and function of the glomerular mesangium. J Am Soc Nephrol 2:S65-S73

29. Ellis EN, Steffes MW, Goetz FC, Sutherland DE, Mauer SM (1986) Glomerular filtration surface in type I diabetes mellitus. Kidney Int 29:889-894

30. Chavers BM, Bilous RW, Ellis EN, Steffes MW, Mauer SM (1989) Glomerular lesions and urinary albumin excretion in type I diabetes without overt proteinuria. N Engl J Med 320:966-970

31. Walker JD, Close CF, Jones SL et al (1992) Glomerular structure in type-1 (insulin-dependent) diabetic patients with normo- and microalbuminuria. Kidney Int 41:741-748

32. Nyengaard JR, Bendtsen TF (1992) Glomerular number and size in relation to age, kidney weight, and body surface in normal man. Anat Rec 232:194-201

33. Osterby R, Gundersen HJ (1975) Glomerular size and structure in diabetes mellitus. I. Early abnormalities. Diabetologia 11:225-229

34. White KE, Pinel N, Cordonnier DJ, Bilous RW (2001) Does ACE inhibition slow progression of glomerulopathy in patients with type 2 diabetes mellitus? Diabet Med 18:933-936

35. Schmidt K, Pesce C, Liu Q et al (1992) Large glomerular size in Pima Indians: lack of change with diabetic nephropathy. J Am Soc Nephrol 3:229-235
36. Abdi R, Slakey D, Kittur D, Racusen LC (1998) Heterogeneity of glomerular size in normal donor kidneys: impact of race. Am J Kidney Dis 32:43-46

37. Hoy WE, Hughson MD, Singh GR, Douglas-Denton R, Bertram JF (2006) Reduced nephron number and glomerulomegaly in Australian Aborigines: a group at high risk for renal disease and hypertension. Kidney Int 70:104-110

38. Hostetter TH, Rennke HG, Brenner BM (1982) The case for intrarenal hypertension in the initiation and progression of diabetic and other glomerulopathies. Am J Med 72:375-380

39. Osterby R, Gundersen HJ (1980) Fast accumulation of basement membrane material and the rate of morphological changes in acute experimental diabetic glomerular hypertrophy. Diabetologia 18:493-500

40. Riser BL, Cortes P, Zhao X, Bernstein J, Dumler F, Narins RG (1992) Intraglomerular pressure and mesangial stretching stimulate extracellular matrix formation in the rat. J Clin Invest 90:1932-1943

41. Parving HH, Kastrup H, Smidt UM, Andersen AR, FeldtRasmussen B, Christiansen JS (1984) Impaired autoregulation of glomerular filtration rate in type 1 (insulin-dependent) diabetic patients with nephropathy. Diabetologia 27:547-552

42. Christensen PK, Hansen HP, Parving HH (1997) Impaired autoregulation of GFR in hypertensive non-insulin dependent diabetic patients. Kidney Int 52:1369-1374

43. Schmitz A, Christensen T, Taagehoej Jensen F (1989) Glomerular filtration rate and kidney volume in normoalbuminuric noninsulin-dependent diabetics - lack of glomerular hyperfiltration and renal hypertrophy in uncomplicated NIDDM. Scand J Clin Lab Invest 49:103-108

44. New JP, Marshall SM, Bilous RW (1998) Renal autoregulation is normal in newly diagnosed, normotensive, NIDDM patients. Diabetologia 41:206-211

45. Arendshorst WJ, Beierwaltes WH (1979) Renal and nephron hemodynamics in spontaneously hypertensive rats. Am J Physiol 236:F246-F251

46. Kimura G, Imanishi M, Sanai $T$ et al (1991) Intrarenal hemodynamics in patients with essential hypertension. Circ Res 69:421-428

47. Keller G, Zimmer G, Mall G, Ritz E, Amann K (2003) Nephron number in patients with primary hypertension. N Engl J Med 348:101-108

48. Bell ET (1953) Renal vascular disease in diabetes mellitus. Diabetes 2:376-389

49. Fogo A, Breyer JA, Smith MC et al (1997) Accuracy of the diagnosis of hypertensive nephrosclerosis in African Americans: a report from the African American Study of Kidney Disease (AASK) Trial. AASK Pilot Study Investigators. Kidney Int 51:244-252

50. Osterby R, Hartmann A, Bangstad HJ (2002) Structural changes in renal arterioles in Type I diabetic patients. Diabetologia 45:542-549

51. Olsen S, Mogensen CE (1996) How often is NIDDM complicated with non-diabetic renal disease? An analysis of renal biopsies and the literature. Diabetologia 39:1638-1645

52. Kampmann JP, Hansen JM (1981) Glomerular filtration rate and creatinine clearance. Br J Clin Pharmacol 12:7-14 